\title{
THE AUTONOMIC INNERVATION OF RAT BRACHIAL ARTERY AND VEIN
}

\author{
Francesco amenta, Garlo CaVallotti, Marco de ROSSi \\ and Francesco VATRELLA \\ Laboratorio di Neurobiologia, Istituto di Anatomia Umana Normale and \\ Dipartimento di Scienze Neurologiche dell'Universita de Roma \\ "La Sapienza", Rome, Italy
}

Received for publication March 23, 1983 and in revised form June 1983

\begin{abstract}
The distribution pattern of quinacrine-positive, catecholamine-containing and acetylcholinesterase-positive nerve fibers was investigated in the rat brachial artery and vein using the quinacrine histofluorescence, the formaldehyde-induced fluorescence and the acetylcholinesterase histochemical methods, respectively.

Some animals were chemically sympathectomized using the neurotoxin 6-hydroxydopamine in order to ascertain the nature of the different kinds of nerve fibers visualized. The density of innervation between artery and vein as well as between the various portions of single blood vessels was studied using quantitative image analysis.

No quinacrine-positive nerve fibers were found within rat brachial artery and vein. On the contrary both blood vessels were supplied by adrenergic and acetylcholinesterase-containing (likely cholinergic) nerve fibers. The pretreatment of samples with quinacrine did not alter the intensity of the reaction neither the distribution pattern of nerve fibers, revealed with other histochemical techniques.

The quantitative image analysis showed that the brachial artery is provided with an adrenergic innervation, richer of about $30 \%$ than corresponding vein. In the artery the adrenergic innervation was more developed of the cholinergic one of about $20 \%$ and in the vein of about $15 \%$. The artery is provided with a cholinergic innervation richer than corresponding vein of about $25 \%$. The density of nerve fibers decreases gradually proceeding towards the distal ends of studied blood vessels.
\end{abstract}

In spite of the practical importance of a detailed knowledge of the innervation pattern of upper limbs blood vessels for the study of the pathogenesis of finger's vasospastic phenomena as well as of the Raynaud's phenomenon $(6,12,19)$, no extensive information is still available on the argument.

In view of this, the innervation pattern of rat brachial artery and vein was studied using a combined histochemical and quantitative image analysis method.

\section{MATERIALS AND METHODS}

Ten Sprague-Dawley rats of $250-300 \mathrm{gr}$ were employed. Five animals were 
chemically sympathectomized using the neurotoxin 6-hydroxydopamine (6-OHDA, for references see 17). The neurotoxin was dissolved in a saline solution containing $0.1 \mathrm{mg} / \mathrm{ml}$ ascorbic acid and injected in two intraperitoneal doses of $200 \mathrm{mg} / \mathrm{kg}$ each one. The second injection was given $24 \mathrm{hr}$ after the first one. The animals were sacrificed $24 \mathrm{hr}$ after the last injection by ether overdose. The other control animals received two 6-OHDA free injections.

The upper limb was dissected and the brachial artery and vein together with their main branches were removed and washed in a Krebs Ringer solution (KR) prepared according to instructions of Hamberger (15) for 3-5 min at $4^{\circ} \mathrm{C}$.

Some specimens were incubated in the same $\mathrm{KR}$ solution as above containing $5 \times 10^{-7} \mathrm{M}$ quinacrine in order to visualize nerve fibers with a selective affinity for the drug (20). The incubation was done at $37^{\circ} \mathrm{C}$ for $30 \mathrm{~min}$. The blood vessels were washed and processed as whole mounts or cryostat sections of 15-30 $\mu \mathrm{m}$ according to the procedure described in an earlier paper (1) but without mounting. The specimens were then observed and photographed on a fluorescence microscope equipped with an epi-illumination system (see 1). After quinacrine histochemistry the whole mounts and the sections were dried in vacuo under $\mathrm{P}_{2} \mathrm{O}_{5}$ and exposed to formaldehyde vapours to visualize adrenergic nerve fibers (13). The pieces were exposed to formaldehyde for $180 \mathrm{~min}$ at $37^{\circ} \mathrm{C}$ in order to avoid the inactivation of the acetylcholinesterase activity to be subsequently demonstrated in the same histological specimens (see 21). Finally, after catecholamine histofluorescence, both whole mounts and sections were processed for the histochemical demonstration of acetylcholinesterase activity according to the method published in a previous paper (3). The incubation was done at room temperature for 90-120 min in a medium containing $10^{-5} \mathrm{M}$ iso-OMPA as an inhibitor of non specific cholinesterases.

The other specimens were processed separately and not consecutively for the detection of quinacrine and catecholamine histofluorescence as well as for the histochemical demonstration of acetylcholinesterase activity according to the procedure described above. However, for the demonstration of tissue stores of catecholamines, the pieces were exposed to formaldehyde vapours at a temperature of $80^{\circ} \mathrm{C}$ for $60 \mathrm{~min}$.

The whole mounts from catecholamine and acetylcholinesterase histochemistry were examined using a MOP III (Carl Zeiss) image analyzer according to the method proposed by Cowen and Burnstock (7) modified for our purposes. Briefly, three arbitrary fields of each preparation were photographed on a Zeiss II photomicroscope equipped with an epi-illumination system for fluorescence observations and/or transmitted light illumination system for other observations. A planapochromat $\times 25 / 0.65$ objective and a 1.6 optovar to obtain a final magnification at the camera of $\times 125$ were employed. Ilford PAN F black and white film was used for photography and microphotographies were developed to obtain maximum contrast. Prints were enlarged at a size of $18 \times 24$ to make possible an easier evaluation of morphometric parameters. The following parameters were evaluated for each microphotography: 1) total area occupied from nerve fibers (expressed as a percentage of the total surface area); 2) intercept density (expressed as the number of nerves for millimeter of line length screened by the image analyzer divided by the magnification); 3) number and perimeter of varicosities for pictures from catecholamine histofluorescence experiments (see 7). 


\section{RESULTS}

No nerve fiber-like fluorescence was observed within the wall of rat brachial artery or vein when incubated in the presence of quinacrine (Fig. 1).

Sections and whole mounts from brachial artery and vein developed fluorophores in adrenergic nerves when exposed to formaldehyde vapours. No significant differences were found in the intensity of fluorescence, in the total area occupied from fluorescent nerve fibers, in the intercept density as well as in the number and perimeter of varicosities between specimens of blood vessels processed for catecholamine histofluorescence after exposure or not to quinacrine (Figs. 2, 3 and Table 1).

The brachial artery appears to be provided with a richer adrenergic innervation than the corresponding vein (Fig. 4 and Table 1). Moreover the density of fluorescent nerve fibers was higher in the proximal portions of the blood vessels than in distal ones (Table 1).

Concerning the distribution pattern of fluorescent nerve fibers within the various layers of studied blood vessels, they are organized in a 2-dimensional network-like plexus at the adventitial-medial border. The plexus appears to be arranged in a band approximately $5-8 \mu \mathrm{m}$ wide in the artery and $3-5 \mu \mathrm{m}$ wide in the vein (Figs. $5,6)$.

The treatment with the neurotoxin 6-OHDA determines the disappearance of any catecholamine histofluorescence confirming the adrenergic nature of fluorescent nerve fibers.

Sections and whole mounts of brachial artery and vein incubated for the demonstration of acetylcholinesterase activity developed a dark-brown precipitate in nerve fiber-like structures primarily within the artery wall. The distribution pattern of acetylcholinesterase-containing nerve fibers appears to be very different

TABLE 1. Comparison of adrenergic plexus density in whole mounts of rat brachial artery and vein

\begin{tabular}{|c|c|c|c|c|c|c|c|c|}
\hline \multirow{3}{*}{$\begin{array}{l}\text { PARAMETERS } \\
\text { EXAMINED }\end{array}$} & \multicolumn{4}{|c|}{ BRACHIAL ARTERY } & \multicolumn{4}{|c|}{ BRACHIAL VEIN } \\
\hline & \multicolumn{2}{|c|}{ PROXIMAL } & \multicolumn{2}{|c|}{ DISTAL } & \multicolumn{2}{|c|}{ PROXIMAL } & \multicolumn{2}{|c|}{ DISTAL } \\
\hline & $\mathrm{AQ}$ & $W Q$ & $\overline{A Q}$ & WQ & $\mathrm{AQ}$ & WQ & $\mathrm{AQ}$ & $W Q$ \\
\hline $\begin{array}{l}\text { FLUORESCENT } \\
\text { AREA }{ }^{\circ}:\end{array}$ & $\begin{array}{l}15.4 \\
\pm 0.8\end{array}$ & $\begin{array}{l}14.8 \\
\pm 0.1\end{array}$ & $\begin{array}{l}10.3 \\
\pm 0.2\end{array}$ & $9.2 \pm 0.6$ & $\begin{array}{l}10.6 \\
\pm 0.9\end{array}$ & $9.8 \pm 0.9$ & $6.7 \pm 0.1$ & $6.5 \pm 0.4$ \\
\hline $\begin{array}{l}\text { INTERCEPT } \\
\text { DENSITY }\left(\mathrm{mm}^{-1}\right)\end{array}$ & $\begin{array}{l}88.4 \\
\quad \pm 6.5\end{array}$ & $\begin{aligned} 82.8 \\
\therefore .0\end{aligned}$ & $\begin{array}{l}66.9 \\
\pm 9.4\end{array}$ & $\begin{array}{l}63.3 \\
\quad \pm 6.0\end{array}$ & $\begin{array}{l}60.3 \\
\pm 4.1\end{array}$ & $\begin{array}{l}57 . \pm \\
\pm 8.0\end{array}$ & $\begin{array}{l}39.5 \\
\pm 7.2\end{array}$ & $\begin{array}{r}38.3 \\
\pm 5.9\end{array}$ \\
\hline $\begin{array}{l}\text { NUMBER OF } \\
\text { VARICOSITIES } \\
\quad\left(\mathrm{mm}^{-2}\right)\end{array}$ & $\begin{array}{l}13,681 \\
+608\end{array}$ & $\begin{array}{l}13,037 \\
\pm 407\end{array}$ & $\begin{array}{l}8,612 \\
\quad \pm 403\end{array}$ & $\begin{array}{l}8,560 \\
\pm 334\end{array}$ & $\begin{array}{l}8,002 \\
+309\end{array}$ & $\begin{array}{l}7,875 \\
\pm 200\end{array}$ & $\begin{array}{l}7,102 \\
\pm 243\end{array}$ & $\begin{array}{l}6,484 \\
\pm 291\end{array}$ \\
\hline $\begin{array}{l}\text { PERIMETER OF } \\
\text { VARICOSITIES } \\
\qquad(\mu \mathrm{m})\end{array}$ & $4.0 \pm 0.7$ & $4.0 \pm 0.3$ & 4. $1 \pm 0.9$ & $3.9_{ \pm 0} 0$. & $3.7 \pm 0.3$ & $3.7 \pm 0.7$ & $3.7 \pm 0.3$ & $3.6 \pm 0$ \\
\hline
\end{tabular}

Each value represents the mean of 10 determinations carried out in triplicate $\pm S$. $D$. The length of each blood vessel was about $2.1 \pm 0.6 \mathrm{~cm}$. Each blood vessel was divided in two portions of 1.1 $\pm 0.5 \mathrm{~cm}$ each one. The artery and/or the vein were dissected out at the lower border of the tendon of the teres major that was considered as the proximal portion of the blood vessels. $\mathrm{AQ}=$ after quinacrine incubation; $\mathrm{WQ}=$ whithout quinacrine pre-treatment. Fluorescent area is the $\%$ of total surface area occupied by fluorescent nerve fibers. Intercept density is the reciprocal of mean distance in $\mathrm{mm}$ between nerves. 


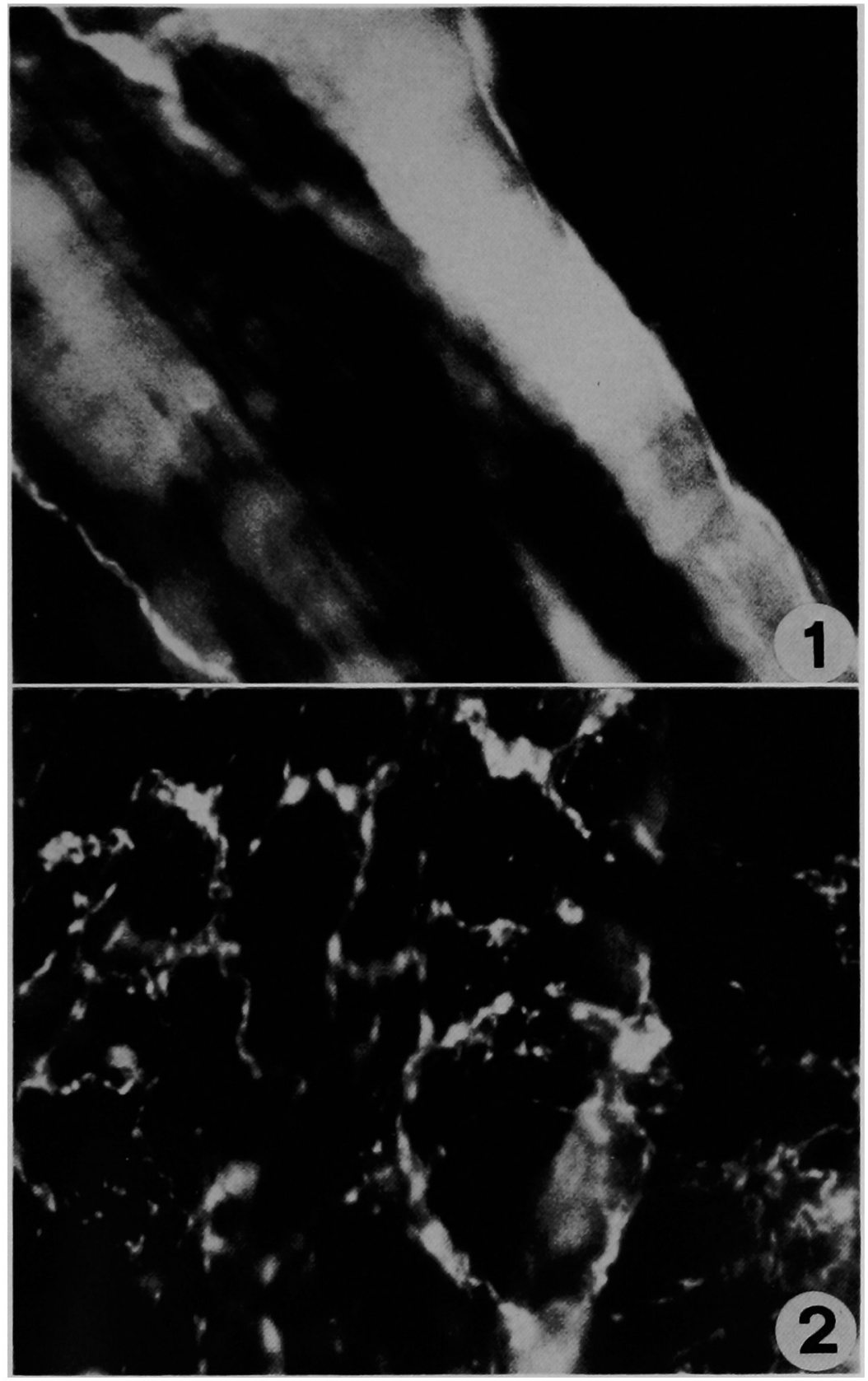

Fig. 1. Rat brachial artery incubated with $5 \cdot 10^{-7} \mathrm{M}$ quinacrine. Whole mount. The background fluorescence is remarkably increased but no nerve fiber-like structures can be seen. $\quad 350$ Fig. 2. Rat brachial artery. Catecholamine histofluorescence. Whole mount. Proximal portion. Adrenergic nerve fibers are organized in a dense plexus rich of varicosities. $\quad \mathbf{3 5 0}$ 


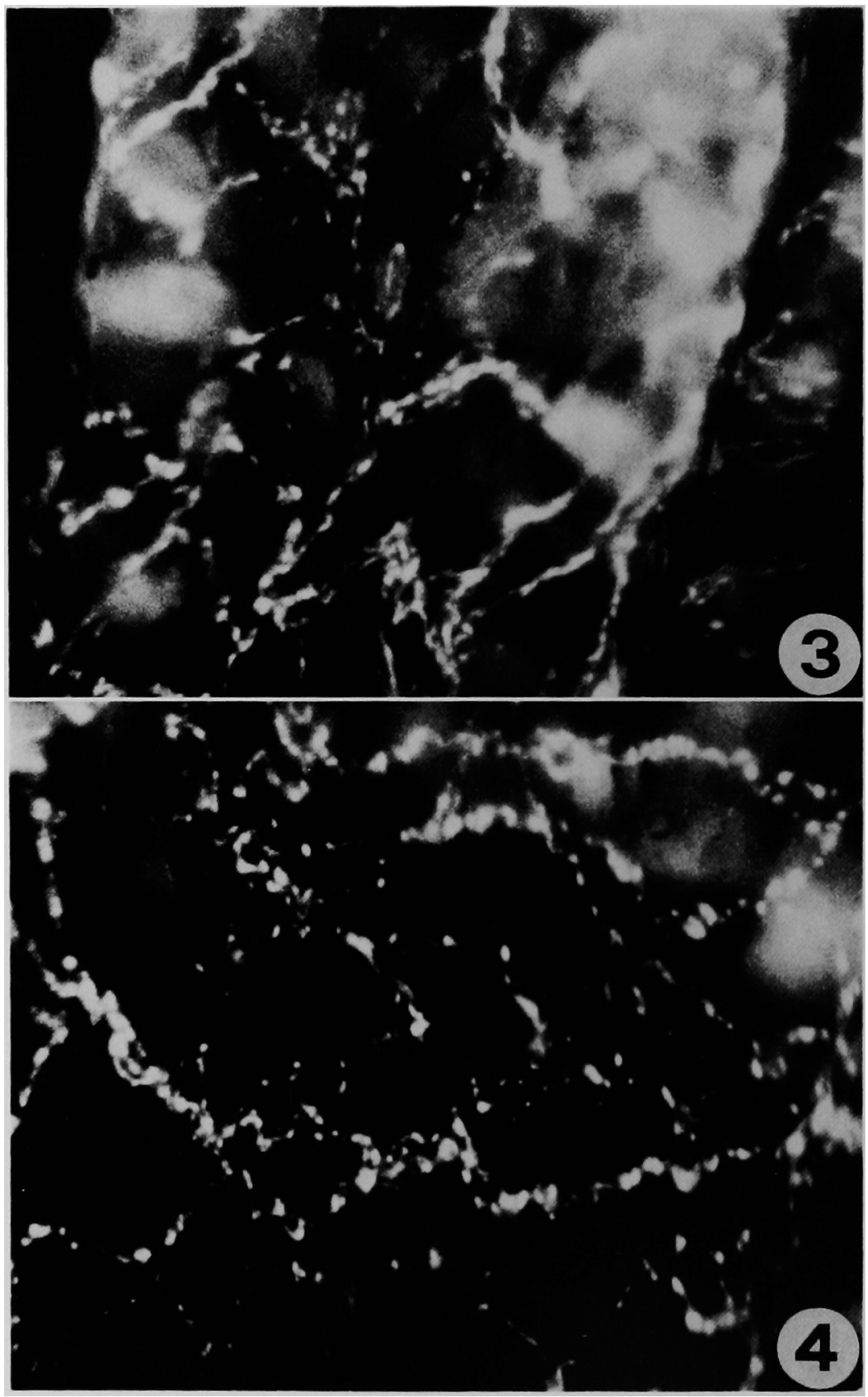

FIG. 3. Rat brachial artery incubated with quinacrine and then processed for the consecutive histochemical detection of catecholamine histofluorescence. Whole mount. Proximal portion. The pre-treatment with quinacrine does not determine any alteration in the density and distribution pattern of adrenergic nerve fibers. However, after quinacrine, the background fuorescence appears to be increased. $\quad 350$

FIG. 4. Rat brachial vein. Catecholamine histofluorescence. Whole mount. Proximal portion. The vein is supplied by a sparse plexus of adrenergic nerve fibers rich of varicositics. $\quad 350$ 


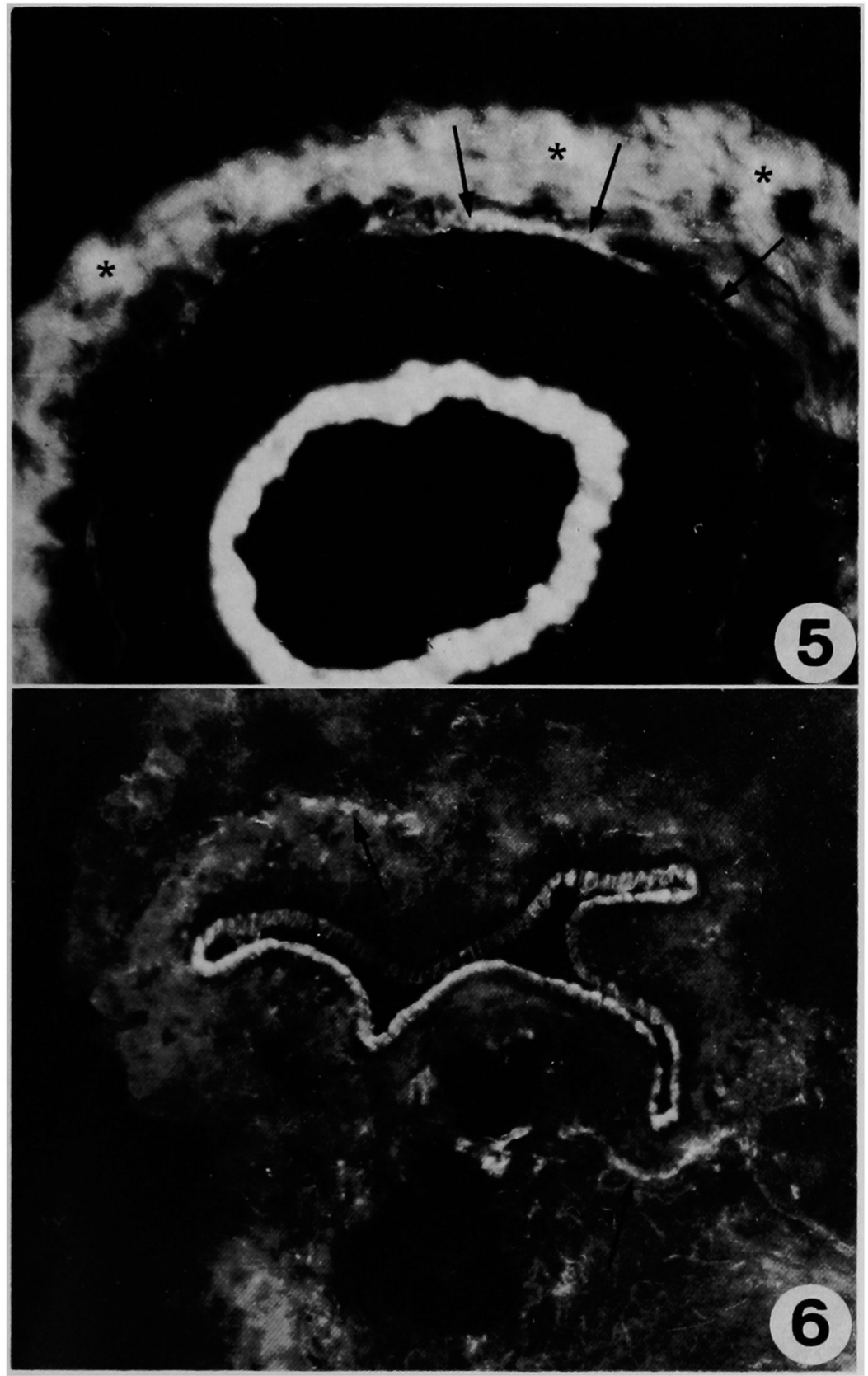

FIG. 5. Rat brachial artery. Catecholamine histofluorescence. Transverse section. The plexus of adrenergic nerve fibers is localized in the adventitial-medial transitional zone (arrows). The asterisks indicate the periadventitial tissue showing an intense autofluorescence. $\quad 240$

Fig. 6. Rat brachial vein. Catecholamine histofluorescence. Transverse section. Also in the vein the plexus of adrenergic nerve fibers was found at the adventitial-medial transitional zone (arrows). $\succ 200$ 


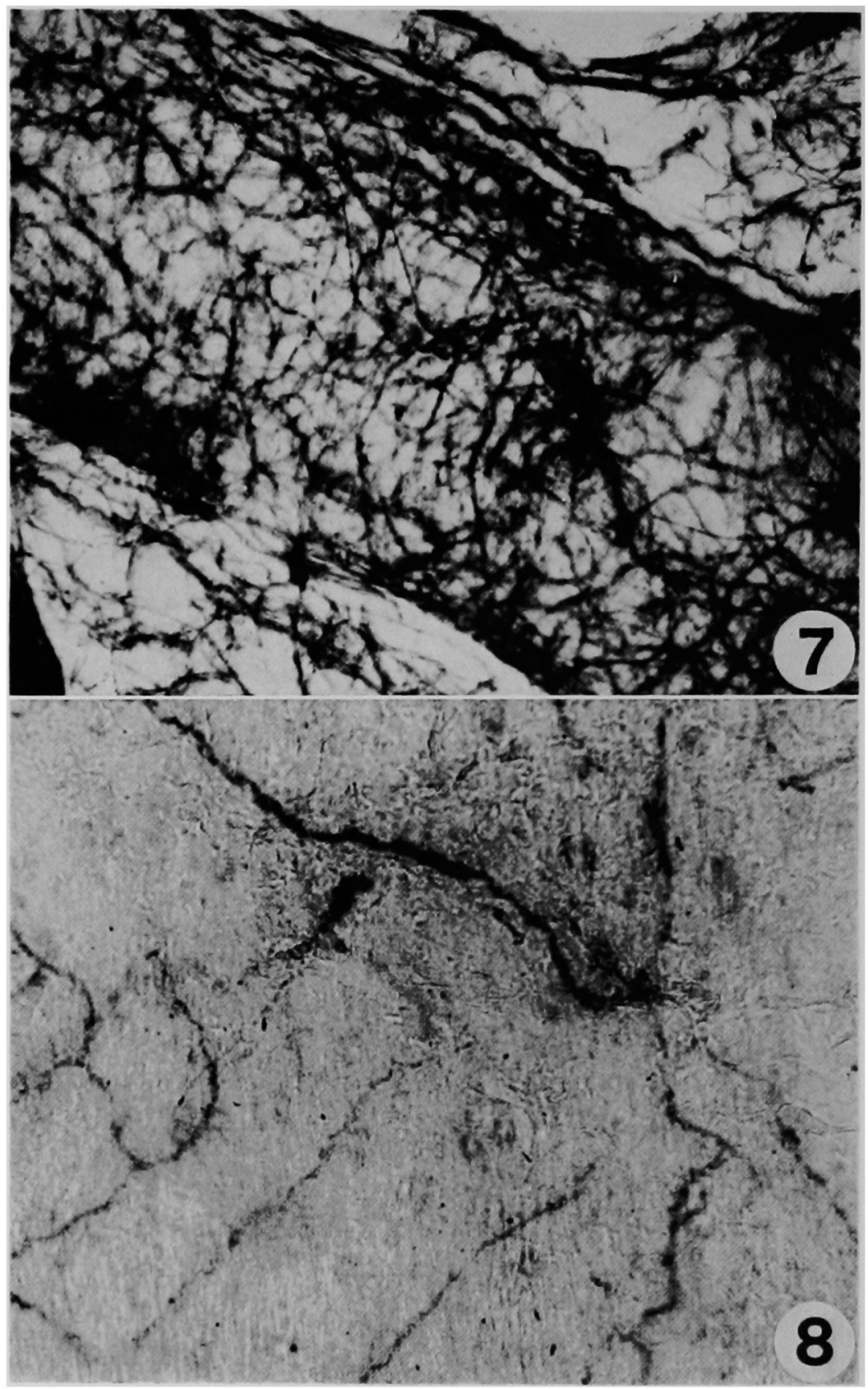

FIG. 7. Rat brachial artery incubated with quinacrine and then processed for the consecutive histochemical detection of catecholamine histofluorescence and of acetylcholinesterase activity. Whole mount. Proximal portion. Acetylcholinesterase activity is localized in nerve fiber-like structures organized in dense plexus. 65

FIG. 8. Brachial vein from a chemically sympathectomized rat. Acetylcholinesterase. Whole mount. Distal portion. 220 
TABLE 2 Comparison of acetylcholinesterase-positive plexus density in whole mounls of rat brachial artery and vein

\begin{tabular}{|c|c|c|c|c|}
\hline & & & $\begin{array}{c}\text { AREA OCCUPIED } \\
\text { BY NER VE FIBERS } \\
0_{n}\end{array}$ & $\begin{array}{l}\text { INTERCEPT } \\
\text { DENSITY } \\
\left(\mathrm{mm}^{-1}\right)\end{array}$ \\
\hline \multirow{6}{*}{$\begin{array}{l}\text { BRACIHIAL } \\
\text { ARTERY }\end{array}$} & \multirow{3}{*}{ PROXIMAI. } & $\mathrm{AQ}$ & $11.9 \pm 0.5$ & $72.5 \pm 8.7$ \\
\hline & & $W(2$ & $11.4 \pm 0.3$ & $67.2 \pm 6.0$ \\
\hline & & $\mathrm{W}^{\prime}(2+60 \mathrm{HDA}$ & $11.6 \pm 0 . t$ & $69.0 \leq 7.3$ \\
\hline & \multirow{3}{*}{ DISTAL. } & $A Q$ & $8.6 \pm 0.8$ & $51.9 \pm 2.6$ \\
\hline & & WQ & $8.8+0.7$ & $50.4 \cdots 4.7$ \\
\hline & & $\| \mathrm{Q}+60 \mathrm{HDA}$ & $8.9 \pm 0.2$ & $52.3 \pm 7.1$ \\
\hline \multirow{6}{*}{$\begin{array}{l}\text { BRACHIAL } \\
\text { VEIN }\end{array}$} & \multirow{3}{*}{ PRONIMAL } & $\mathrm{A} Q$ & $8.2 \pm 0.5$ & $56.2 \div 7.4$ \\
\hline & & WQ & $8 .+0.3$ & $55.9 \pm t .0$ \\
\hline & & $\mathrm{WQ}+60 \mathrm{HDA}$ & $8.0+0.9$ & $54.3 \pm 4.5$ \\
\hline & \multirow{3}{*}{ DISTAL. } & $A Q$ & $7.0_{-} 0.6$ & $+0.3 \pm 3.2$ \\
\hline & & $W Q$ & $6.9 \pm 0.9$ & $40.6 \pm 5.6$ \\
\hline & & $W Q+60 \mathrm{HDA}$ & $6.9 \pm 0.2$ & $42.4 \pm 3.9$ \\
\hline
\end{tabular}

Each value represents the mean of 10 determinations carried out in triplicate $\pm S$.D.. The length of each blood vessel was about $2.1+0.6 \mathrm{~cm}$. Each blood vessel was divided in two portions of $1.1 \pm 0.5 \mathrm{~cm}$ each one. The artery and/or the vein were dissected out at the lower border of the tendon of the teres major that was considered as the proximal portion of the blood vessels.

$\mathrm{AQ}=$ after quinacrine incubation; $1 \mathrm{Q}=$ = without quinacrine pre-treatment; $1 \mathrm{Q}+60 \mathrm{HDA}$ sympathectomized rat (specimen without quinacrine pre-treatment). For further details see materials and methods.

from those described above for adrenergic nerve supply. The brachial artery is provided with a network-like plexus of acetylcholinesterase positive nerve fibers while a poorly developed plexus supplies the brachial vein (Figs. 7, 8 and Table 2). The innervation shows a decrease proceeding in proximo-distal sense (Table 2 ). No differences in the intensity of acetylcholinesterase staining or in the density pattern of nerve fibers were found between specimens pretreated or not with quinacrine and formaldehyde before acetylcholinesterase histochemistry (Table 2).

Acetylcholinesterase-containing nerve fibers are confined at the adventitialmedial border and are arranged in a band approximately $4-6 \mu \mathrm{m}$ wide in the artery and $1-3 \mu \mathrm{m}$ wide in the vein.

The chemical sympathectomy does not determine alteration in the distribution pattern of acetylcholinesterase-positive nerve fibers or in the intensity of the staining of enzymatic activity (Table 2 ).

\section{DISCUSSION}

The results reported here provide an evidence that both brachial artery and vein are innervated by adrenergic and acetylcholinesterase-containing nerve fibers while are not supplied by quinacrine-positive nerves.

Concerning the nature of acetylcholinesterase-positive nerve fibers visualized in the present study, the findings that they appear to have a diffierent distribution pattern from adrenergic nerves (as evaluated in pieces consecutively stained for 
catecholamine histofluorescence and acetylcholinesterase) as well as the observation that they are unaltered by chemical sympathectomy are indicative of a non-adrenergic nature (for references see 2,4). On the other hand, the findings that acetylcholinesterase activity was visualized using short incubation times and standard reaction condition are very likely indicative of the parasympathetic nature of enzyme positive nerve fibers stained (for references see 2, 4, 10).

Thus differently from the saphenous. superficial epigastric and tail arteries in which the 6-OHDA treatment caused the almost complete disappearance of acetylcholinesterase-positive nerve fibers (see 1), both brachial artery and vein are supplied by acetylcholinesterase-positive nerve fibers independently of the sympathetic nervous system.

Our findings showing no nerve fiber-like structures in blood vessels specimens incubated with quinacrine are indicative of the absence of nerve fibers with a selective affinity for the drug $(5,20)$ within brachial artery and vein. The pretreatment of blood vessels with quinacrine did not cause alteration in the intensity of the reaction or in the distribution pattern of both catecholamine of acetylcholinesterasepositive nerve fibers (Tables 1 and 2). Accordingly, in spite of the absence of quinacrine-positive nerve fibers, this observation suggested a deeper study in order to standardize a protocol for the consecutive demonstration of quinacrinergic, adrenergic and acetylcholinesterase-positive nerve fibers in the same section as well established for adrenergic and cholinergic nerves by other authors $(11,16,18,22,24)$.

In order to analyze the density of autonomic innervation of brachial artery and vein, a quantitative image analysis method was employed. This method developed by Cowen and Burnstock (7) has been widely applied to the study of vascular innervation and provided very interesting information concerning the density of adrenergic innervation of various circulatory districts in normal and in different experimental conditions $(7,8,14)$. Using the quantitative method, the different distribution and density of adrenergic innervation between brachial artery and vein was evaluated in detail (see Table 1). On the other hand, by applying the quantitative method the density and pattern of cholinergic innervation of brachial artery and vein was established as well. Surely the cholinesterase histochemical method is devoid of the high sensitivity of catecholamine histofluorescence technique. However, simple morphometric parameters such as the total area occupied by nerve fibers and the intercept density may provide a quantitative idea of the extent of cholinergic nerve supply to studied blood vessels.

Finally, the quantitative histochemical observations demonstrating the existence of a cholinergic mechanism (functionally considered as vasodilator, for references see 23) may support the basis for future studies aimed to clarify the pathogenesis of upper limbs vasospastic phenomena and to evaluate alternative treatments for this type of autonomic dysfunction.

\section{ACKNOWLEDGMENTS}

The present study was supported by a grant of Italian Ministero della Pubblica Istruzione and by a grant of Consiglio Nazionale delle Ricerche. The kind help of the staff of the Laboratorio di Neurobiologia and of Dr. Roberto Massa in the revision of the manuscript are gratefully acknowledged. 


\section{REFERENCES}

1. Amenta, F., Cantagalli, A., Cavallotti, C., De Luca, C. and Fiorenti, C.: Autonomic innervation of three rat muscular arteries. Acta histochem. cytochem. 16; 59, 1983.

2. Amenta, F., Cavallotti, C., De Rossi, M., Evangelisti, F. and Ferrante, F.: Acetylcholinesterasecontaining nerve fibers in guinea pig ovary. J. Neural Transm. 52; 295, 1981.

3. Amenta, F., Porcelli, F. and Ferrante, F.: Histochemical studies on the autonomic innervation of the femoral artery and vein. .Inat. Embriol. $157 ; 231,1979$.

4. Amenta, F., Sancesario, G., Ferrante, F. and Cavallotti, C.: Acetylcholinesterase-containing nerve fibers in the dura mater of guinea pig, mouse and rat. J. Neural Transm. 47; 237, 1980.

j. Burnstock, G., Chamley, J. H. and Campbell, G. R.: The innervation of arteries. In Structure and Function of Circulation, ed. by C. J. Schwartz, N. T. Werthessen, \& S. Wolf, vol. 10. Plenum Press, New York, 1980.

6. Cohen, R. A. and Coffman, I. D.: $\beta$-Adrenergic vasodilator mechanism in the finger. Circ. Res. 49; 1196, 1981.

7. Cowen, T. and Burnstock, G.: Quantitative analysis of the density and pattern of adrenergic innervation of blood vessels. Histochemistry 66;19, 1980.

8. Cowen, T., Haven, A. J., Cai Wen-Qin, Gallen, D. D., France, F. and Burnstock, G.: Development and ageing of perivascular adrenergic nerves in the rabbit. A quantitative fluorescence histochemical study using image analysis. J. Autonomic Nervous System 5; 317, 1982.

9. Crowe, R. and Burnstock, G.: Perinatal development of quinacrine-positive neurons in the rabbit gastrointestinal tract. J. Autonomic Nerious System 4; 217, 1981.

10. Ehinger, B.: Cholinesterases in ocular and orbital tissues of some mammals. Acta Lnit. Lund $11 ; 201,1966$.

11. El-Badawi, A. and Schenk, E. A.: Histochemical methods for separate, consecutive and simulataneous demonstration of acetylcholinesterase and norepinephrine in cryostat sections. $I$. Histochem. Cytochem. 15; 580, 1967.

12. Eliasson, K., Lins, L.-E. and Sundqvist, K.: Vasospastic phenomena in patients treated with beta-adrenoreceptor blocking agents. Acta Med. Scand. (Suppl.) 628; 39, 1979.

13. Falck, B., Hillarp, N.-A. Thieme, G. and Torp, A.: Fluorescence of catecholamines and related compounds condensed with formaldehyde. J. Histochem. Cytochem. 10; 348, 1962.

14. Griffith, S. G., Crowc, R., Lincoln, J., Haven, A. J. and Burnstock, G.: Regional differences in the density of perivascular nerves and varicosities, noradrenaline content and responses to nerve stimulation in the rabbit ear artery. Blood Vessels $19 ; 41,1982$.

13. Hamberger, B.: Reserpine-resistant uptake of catecholamines in isolated tissues of the rat. A histochemical study. Acta physiol. scand. Suppl. 295; 1, 1967.

16. Jacobowitz, D. and Koelle, G. B.: Demonstration of both acetylcholinesterase (AChE) and catecholamines in same nerve trunk. Pharmacologist 5; 270, 1963.

17. Jonsson, $C_{3}$ : Chemical neurotoxin as denervation tools in neurobiology. Amn. Rev. Neurosci. 3: 69, 1980.

18. Kobayashi, S., Tsukahara, S., Sugita, K. and Nagata, T.: Adrenergic and cholinergic innervation of rat cerebral arteries. Histochemistrv 70;129, 1981.

19. Marshall, A. J., Roberts, C.J. C. and Barrett, D. W.: Raynaud's phenomenon as a side effect of beta-blockers in hypertension. Br. Med. J. 1; 1498, 1976.

20. Olson. L., Alund, H. and Norberg, K. A.: Fluorescence-microscopical demonstration of a population of gastro-intestinal nerve fibers with a selective affinity for quinacrine. Cell Tiss. Res. $171 ; 407,1976$.

21. Tervo, T.: Consecutive demonstration of nerves containing catecholamine and acetylcholinesterase in the rat cornea. Histochemistry 50;291, 1977.

22. Waris, T. and Rechardt, L.: Histochemically demonstrable catecholamines in nerve fibres of rat dorsal skin. Histochemistry 50; 203, 1977. 
23. Willems, J. L. and Bogaert, M. G.: Neurogenic vasodilatation. Gen. Pharmac, 9; 223, 1978.

24. Yamauchi, A. and L.ever, J. D.: Correlations between formol fluorescence and acetylcholinesterase $(\mathrm{AChE})$ staining the superior cervical ganglion of normal rat, pig and sheep. J. Anal. 110; $435,1971$. 